\title{
Psychoanalysis in Post-Apartheid South Africa
}

\author{
Elda Storck-van Reenen and Mary-Anne Smith (Cape Town)
}

\begin{abstract}
The following paper seeks to describe the trajectory of psychoanalytic endeavours in South Africa since the political thaw of the 1990s. The first part, written by Elda Storck - van Reenen, centres on the alignment of psychoanalytic training to international standards and the formation of institutions to contain these developments. Encouraging demographic and professional diversity and addressing the deficit of personal therapy - «Selbsterfahrung» - in formal training modalities are of primary importance. The second part, written by MaryAnne Smith, elaborates on the application of basic psychoanalytic concepts to community and outreach work in an impoverished and traumatized society. In addition, the aspiration of engaging the interest and support of governmental agencies around the value and relevance of psychoanalytic thinking for primary and preventative health care is explored.
\end{abstract}

Keywords: political climate change, alignment with international standards, organisations as promoters and containers, diversity, neuropsychoanalysis, mental health systems and interventions, applicability of psychoanalysis, prevention, holding and containment, training of community counsellors, role of psychoanalytic organisations

\section{Networking and Training}

The pre-conditions

At the beginnings of psychoanalysis in South Africa stands the figu re of Wulf Sachs - Russian-born, analyzed by Theodor Reik in Berlin, member of the British Psychoanalytical Society.

He emigrated to South Africa in 1922 where he practiced as a psychoanalyst and founded the South African Psychoanalytic Society, as proudly announced by Sigmund Freud in the postscript to his 1924 Autobiographical Study (Freud, 1935, p. 72). A training programme was established, but with the death of Sachs - its training analyst - in 1949 it was abandoned. The rise of Apartheid contributed to the exodus of many of the Society's members to London to further their training. 
For many years, this was the situation: South Africans interested in psychoanalysis formed reading groups, underwent therapy and supervision with more experienced colleagues and organised sporadic visits from overseas psychoanalysts, mainly from Britain. They found ways to apply their knowledge to psychoanalytically-minded projects and outreach work, also in the disadvantaged communities. Excellent scholars developed centres of learning and gained influence in the psychology departments of many universities. What was lacking was the opportunity to have personal analyses with acknowledged analysts as an integrated element of the learning experience.

Those who wanted an accredited training had to leave the continent. In the 1970s Sydney Press - a wealthy local philanthropist with an avid belief in psychoanalysis - sponsored the training of some South Africans in London, in the hope that they would return. Only a few did and with one exception then changed their minds.

\section{Developments since 1994}

Change only became possible with the momentous political developments in the 90s. In 1994 South Africa transitioned from the system of Apartheid to one of majority rule. A group of London-based expatriates realised the implications of the thaw for psychoanalysis and formed the South African Psychoanalysis Trust (SAPT) with the aim of establishing an accredited training institute in South Africa, thereby bringing it into line with international standards.

In 1998, an International Psychoanalytic Association (IPA)-sponsored conference took place in Cape Town, brought about by the cooperation of SAPT members with local psychoanalytically oriented therapists from Cape Town and Johannesburg.

The declared aim of the conference organising committee was "to reach out to as wide a South African audience as possible in order to spread awareness of psychoanalytic thinking, and to provide a setting in which its relevance in present day South Africa may be considered" (Ivey, 1998, p. 53).

The dynamics at this conference are worthwhile accounting in some detail, because they demonstrate the rift felt between those who had remained in relation to those who had left the country. To some extent, these painful feelings can be detected in the local psychoanalytic community even to this day.

One of the key group dynamics of the conference was the tension between those who had left to train elsewhere and those who had remained behind during the dark years of Apartheid. These two groups represented conflicting forms of 
authority-overseas psychoanalytic expertise versus local knowledge of community experiences, needs and dynamics. Political exiles reported this same tension in relation to the local activists on their return.

The returning "foreigners" were also seen as parents who had abandoned their children and were now returning with reparative intentions. That the "parents" at times misjudged the ages of their children was inevitable ("why offer us a bottle when we're ready for solids?" one delegate asked). Many locals experienced the visitors as patronising or condescending; the visitors might have seen the locals as ungrateful and envious.

Thirdly, the worth of psychoanalysis in a society racked by poverty and gross inequality was hotly debated. Joseph Sandler remarked that psychoanalysis as a treatment would not accomplish very much, but that hope might lie in the approach as opposed to the method. On the other hand it was recognised that the absence of an institutional container like the IPA promotes anxieties and defences.

The question of whether and how psychoanalysis might benefit the poor is not new. In 1919 Freud had this to say:

We shall probably discover that the poor are even less ready to part with their neuroses than the rich, because the hard life that awaits them if they recover offers them no attraction, and illness gives them one more claim to social help. Often, perhaps, we may only be able to achieve anything by combining mental assistance with some material support... It is very probable, too, that the large-scale application of our therapy will compel us to alloy the pure gold of analysis freely with the copper of direct suggestion... But, whatever form this psychotherapy for the people may take, whatever the elements out of which it is compounded, its most effective and most important ingredients will assuredly remain those borrowed from strict and untendentious psycho-analysis. (Freud, 1919, pp.167-168)

It is thus understandable that analysts who returned to live and work permanently in South Africa approached the situation tentatively. Mark Solms and Karen Kaplan-Solms, who returned in 2002, led this approach by meeting with representatives of local psychoanalytic organisations in Cape Town and Johannesburg, asking how best they could collaborate in bringing an accredited training to South Africa. They were both convinced that psychoanalysis was deeply dependent on a wider 
context of psychoanalytic psychotherapy, as much as they felt that psychoanalytic psychotherapy could not flourish in the absence of psychoanalysis.

These meetings resulted in a number of developments.

The few overseas-trained psychoanalytic psychotherapists and non-IPA analysts who were now working in South Africa renewed their efforts to liaise with the International Psychoanalytic Association IPA in order to apply for Direct Member status within the IPA. ${ }^{1}$

A series of didactic seminars, taking place regularly and focusing on basic psychoanalytic concepts, started in Johannesburg, led by Mark Solms and Kate Aubertin (a Paris-trained member of the IPA who had returned home in 1986). This was followed by a second series of theoretical seminars in which the basic concepts were applied to a study of published clinical case reports.

When Mme Aubertin retired in 2005, the Johannesburg seminar group was transformed to a clinical seminar group, where the case material of the members was presented and discussed in the light of the theoretical groundwork of the earlier seminars. These seminars were led by Mark Solms and Karen Solms. Soon, a parallel group was formed in Cape Town.

It rapidly became necessary to create additional clinical seminar groups in both cities to accommodate the demand for membership and the inevitable boundary problems that arise in psychoanalytic organisations, where therapists and patients are sometimes also colleagues. In 2005/6 all the Johannesburg and Cape Town groups were consolidated to form a single national organization, called the South African Psychoanalysis Initiative (SAPI).

\section{SAPI and the IPA}

The prime objective of this new organization echoed that of the SA Psychoanalysis Trust in London (which had since been dissolved), namely to promote the establishment of an accredited training institute in South Africa. The members pay fees which not only cover the travel costs of the analysts who lead the seminars in Johannesburg and Cape Town, but which are used to build the substantial funds needed to cover the costs of the accreditation process. These costs are high because, following an initial Site Visit funded by the IPA itself, three members nominated by the IPA New Groups Committee visit the applicant group at least twice a year, in order to oversee its progress.

SAPI is thus the mother ship of the Study Group, which was granted formal status at the IPA's $46^{\text {th }}$ Congress in Chicago in July 2009, and was henceforth known 
as the South African Psychoanalytic Association (SAPA). All SAPA members are also members of SAPI, as are all candidates for the training programme.

SAPI currently consists of about 160 members. There are four clinical seminar groups in Johannesburg and three in Cape Town. Additionally, Johannesburg has a SAPI Community Group which started as a low-fee group, mainly for students of psychology who were doing their internship and were interested in a psychoanalytic approach to community work. The University of Cape Town offers a PhD programme in psychoanalysis; two of the students form the core of the Cape Town and Johannesburg SAPI Research Groups.

SAPI holds an annual weekend congress in February, on the Solms-Delta wine farm in Franschhoek, which is well-attended by international colleagues. This tradition was initiated by Jonathan Sklar of London, who acted as convenor for many years. The topic in 2014 was The Embodied Mind, led by Marilia Aisenstein. The 2015 keynote address is by Irma Brenman Pick, on Creativity and Authenticity. A second annual event-Education Day - takes place in Johannesburg in September, devoted to didactic themes.

SAPI celebrates its $10^{\text {th }}$ anniversary in 2015 and will no doubt have a secure place in the future psychoanalytic landscape of this country, beyond the accomplishment of its primary goal of a psychoanalytic training for a minority of its members. The ongoing dedication of those who opted not to train forms an indispensable part of the growing psychoanalytic tradition in South Africa.

SAPA, the training body, currently consists of 8 members, of which 5 have the status of training analysts and supervisors for the region. All 8 members share the other administrative and teaching tasks. There are 15 candidates in training, and 11 provisional candidates waiting for the next round of didactic seminars to commence. Teaching is spread across the two cities, Johannesburg and Cape Town.

\section{The regional confederation of psychoanalytic groups}

Parallel to the formation of SAPA, another milestone in the consolidation of psychoanalytic theory and practice took place. This was the long-awaited formation of a psychoanalytic umbrella body. A number of preparatory regional meetings were held and delegates gathered in Johannesburg on 22 November 2010 to launch this new organization.

In his welcoming address, Prof Gavin Ivey, chair of the steering committee and veteran of similar ventures in the past, enumerated the reasons why this attempt at regional unity might succeed where previous ones had failed. 
Firstly, there had been considerable effort over the years in the establishment of the different study groups represented at the meeting. They had contributed to the training and support of practitioners in South Africa. The number of people practicing psychoanalytic psychotherapy had thus reached sufficient critical mass.

Secondly, Mark and Karen Solms had returned from the UK and established the South African Psychoanalytic Initiative (SAPI), which had led to interest in South Africa as a future IPA member country. This meant that formal psychoanalytic training could now be offered in South Africa.

Thirdly, organizations such as Ububele had made a significant contribution in applying psychoanalysis in community contexts. This had given psychoanalytic work in South Africa greater credibility and mitigated critiques that it is a middle class and elitist treatment modality. ${ }^{2}$

The launch of this organization, the South African Psychoanalytic Confederation (SAPC), represented a consolidation of the years of steady work in a harsh political climate. Dozens of groups joined and worked at creating the constitution and ethical code-from small rural reading groups to large institutes of psychoanalytic learning. It was also a vote of confidence in the future of psychoanalysis in this country and a reflection of the wish to normalize the local situation in an international context. ${ }^{3}$

With its very wide and inclusive catchment area, the SAPC seeks to promote demographic and professional diversity. The member groups of the organization represent clinicians (called "psychoanalytic practitioners") from diverse backgrounds and skill sets.

Nestled within this wide membership, there is a register of those individuals within the organization who have fulfilled the minimal requirements for inclusion on the register. The initial requirements were deliberately set quite low. As the confederation evolved these criteria would be regularly reviewed and in time be amended. Currently they are:

, A minimum of 100 hours of personal individual psychoanalytic psychotherapy in the psychoanalytic tradition of one's own practice preference

, A minimum of 50 hours individual supervision of one's professional practice from a psychoanalytic psychotherapist

, Commitment to ongoing personal therapy and supervision as dictated by personal life circumstances

, Ongoing peer review of clinical practice. The mechanism for this exists in most groups in the form of clinical case presentations and feedback. 
Currently the 40-odd member groups of the SAPC represent more than 500 individuals, of which about two-thirds are on the register.

The SAPC is working towards a situation in the future where a separate category of psychoanalytic practitioner would be legally acknowledged. This is a long-term goal and has to be approached from a variety of perspectives - liaising, collaborating and lobbying in the political sphere.

\section{A new trajectory}

Another noteworthy development within the psychoanalytic community in South Africa is the intensified collaboration between psychoanalysts and neuroscientists as a result of Mark Solms and Karen Solms relocating here. As Head of the Psychology Department at the University of Cape Town, Mark has created a Masters Programme in Neuropsychology and brings his psychoanalytic expertise and passion to the topics of research. The $14^{\text {th }}$ Annual Congress of the International Neuropsychoanalysis Society was held in Cape Town in August 2013 and attracted many newcomers to the field. To quote the NPSA website: Neuropsychoanalysis, the integration of brain and mind, is the new frontier. SAPI runs a research group in Cape Town that focuses on the implications for clinical work of recent neuroscientific revisions of instinct theory and the comparison with Freudian drive theory.

\section{Conclusion}

All over the world, the question of whether psychoanalysis thrives or barely survives is closely bound with the political climate in which it is practised.

The change of government in 1994 effected a great many changes that were also beneficial to the development of a praxis in line with international standards.

South African psychoanalysis is emerging from difficult times with vigour and enthusiasm. Its specific flavour lies in its outreach attempts, in which it is comparable to other countries with widespread poverty and traumatic histories. In spite of rapid societal changes and urbanisation - and the levelling of difference an ethno-psychoanalytic engagement with the many ethnic groupings could foster a better understanding between therapist and patient, across the diverse board. The number of black therapists is on the rise, but nowhere near what is needed to secure a future for psychoanalysis in South Africa. All the efforts described in this paper, among others emanating from universities, are aimed at improving the accessibility of psychoanalysis as a treatment and a line of study. A generation from now, we might be able to report more fully on the specificities of psychoanalysis on African soil. This is our hope and our challenge. 


\section{Psychoanalytic Outreach Work in South Africa}

Psychoanalytic thought has held its own under very unfavourable conditions in this country. That it survived was due to the dedication of many scholars and practitioners. The value and applicability of psychoanalysis in a third world context has been hotly debated by many, including the local psychoanalytic community (now united under the banner of the SAPC). The SAPC is deeply committed to the mental health of all South Africans, and to this end the complex issue of how to use psychoanalytic thinking, if at all, has been a central concern. The capacity to clearly separate "approach" from "method," as suggested by Joseph Sandler at the 1998 conference, has been important.

The attitude of from the couch to the community has been fully embraced by many psychoanalytically orientated therapists in South Africa. The complex issues around the difference between approach and method and what can be usefully used and distilled without loosing the essence of psychoanalytic thinking are held in mind and worked with. These debates have led to a myriad of creative and interesting community projects and solutions that have a palpable impact on the communities they serve. There are a variety of community projects offered that span the life cycle of the individual as well as covering many areas of need in South Africa. Please refer to the Pocket Directory (2012) for a quick reference list of many of the projects.

The context within which these projects are found is important. An estimated 75 percent of South Africans have been exposed to significant trauma (Kaminer \& Eagle, 2011), in addition to social injustices, poverty, and poor education. Combined with the long-term impact of apartheid and intergenerational trauma, South Africa is a society traumatised with significant levels of mental illness. There is a private health system for the wealthy and a public (and very inadequate) system for the poor majority. The public system is supplemented by many community projects provided by charities, non-governmental organizations (NGO's) and the like. Simply, the provision of mental health services to the poor is in a state of crisis and those providing services both within and external to the public health system are overwhelmed.

The need for psychoanalysis as a treatment is also important. There needs to be a balance of highly skilled practitioners, in addition to well trained community workers, to meet the considerable deficit in the heath care system in South Africa. Most South Africans can never have the luxury of a psychoanalytic treatment, but could benefit enormously from well thought through community interventions. High levels of expertise are needed as well as many feet on the ground. Most pro- 
jects are trying to meet overwhelming needs under very difficult if not impossible circumstances. The depth of need, combined with the tenuousness of the work, which is often under threat due to lack of funding and resources, is challenging. In this context it is important that there is a core of individuals who are highly trained to be able to support and assist those actually doing the community work. It can be argued that the demands on the community workers are the most challenging and demanding of all work in the mental health landscape.

In addition to providing a safe, reliable and structured environment, caregivers have to connect emotionally with the unthinkable and often unnamable suffering they encounter. Holding and containment for both the recipients and the providers of the service are important if the mental health care givers are not to regress into manic solutions that are likely to lead to despair or burnout. There is often no concrete external solution for communities in serious crisis where interventions are most needed for victims of xenophobic violence, aids orphans, child headed households, street children, displaced people, sexually abused children where there are few places of safety, and the severely mentally ill.

In community projects psychoanalytic concepts and theory are used as the backbone essential to supporting many projects. The actual detail of what is done in the work may not look particularly sophisticated, but the approach and way in which the project is thought about, and the support and training provided to the mental health practitioners and community workers is grounded in psychoanalytic principles. It is beyond the scope of this article to discuss the detailed thinking and applications of psychoanalytic thinking in each project. Some ideas overlap while others are unique to specific projects.

Concepts that are central to most projects include holding (Winnicott, 1960) and containment (Bion, 1962). Winnicott (1960) describes holding as not just the physical holding of the infant but also a stage of development that includes the total environmental provision that would ultimately determine object relations. The concept and understanding of what it means to provide a holding environment, combined with the transformation of experience through the process of containment as described by Bion (1962), is often what is required in community work.

An example of how the psychoanalytic concepts of holding and containment are used in a community project is the process at Lefika La Phodiso (www. artherapyproject.org). The project trains community art counsellors and provides a number of services, including a holiday programme and art therapy groups for a range of different communities. 
The holiday programme for children of an inner city slum creates significant emotional challenges for the workers, carers and volunteers. Many more children arrive than are expected or catered for. Those in charge are faced with dilemmas such as whether or not to turn children away and what to do with those they cannot accommodate. This is further compounded by how to manage and help the usually traumatized children they do have space for, who are often too disorganized to participate in the activities in the constructive way one would wish them to. These children are in dire need of adult structure, holding and containment. If these concepts are not held firmly in mind, it becomes difficult for the community worker to engage with the activities of the programme.

The training of the community art counsellors is facilitated in an experiential way to provide an experience of both holding and containment (among other psychoanalytic concepts). These counsellors all run groups for children or adults in communities at risk and are faced with equally challenging circumstances.

The practical application of holding and containment is, for example, provided by the supervision groups offered for all the community art counsellors and workers. In turn the supervisors are also offered regular supervisory workshops and work discussion groups. Layers of holding and containment are created by Lefika La Phodiso to provide a space where experiences can be talked about and thought about in the hope that the unthinkable and unmanageable states can be held. Moments of thinking about the chaos and what is stirred up internally are provided. Words or images are not always found, but a space is created where people can come together and try to talk about their experiences and make sense of them, so that a balanced view can be maintained where the rewards and meaning of making a difference can be felt and enjoyed. Without spaces such as these, the risk of burnout is high.

Because of the dire shortage of skilled mental health professionals in South Africa, most community projects are involved in the training of community counsellors and community mental health workers. The core concepts of much of the training include free association, understanding of projection, transference / countertransference, holding, and containment. The various trainings usually include some experience of personal growth such as participation in a group and, when possible, the luxury of some personal counselling or therapy, theoretical and practical training (much of which is experiential), and supervision. While the trainings are all specific to projects, there are core elements that overlap.

A further example of the use of holding and containment is within the South African Psychoanalysis Initiative (SAPI), where clinical seminars are offered for 
newly qualified psychologists and mental health practitioners working in community settings. Each student in South Africa is required to complete one year of community service to register as a psychologist. These young psychologists are thrown into community settings with little support (usually no support) and structure. The plight of these patients is dire, and they are often very traumatized and disturbed with very little access to mental health. The aim of the clinical seminars, in addition to learning and acquiring technical skills, is to provide a holding and containing space to assist these young psychologists in remaining emotionally alive to the contexts in which they find themselves. It is very easy to disconnect from patients and to sink into a sense of demotivation and helplessness about the lack of resources and support for those who are mentally ill. By providing a space to think about and digest their experiences, they are helped to find ways to connect with the suffering of the patients and what interventions might be helpful in this context.

There is a commitment within the SAPC to provide training to non-professional community mental health workers. The aim is to include non-professionals whose training meets standards acceptable for accreditation on the SAPC register. There are discussions underway with the Department of Health to have this SAPC register acknowledged.

The Department of Health's main plan for mental health is the prevention of mental illness and the promotion of mental health. Treatment is limited and currently primarily pharmacological, supplemented by psycho-education with very basic counseling, mainly provided by nurses or community health workers. A combination of budget constraints and inadequate numbers of mental health practitioners, such as psychiatrists and psychologists, further restricts the ability to offer more comprehensive and sophisticated mental health interventions. This is further complicated by the historical impact of apartheid, which means that the demographic of trained mental health professionals does not reflect the demographic of the population.

Psychoanalytic thinking and theory is particularly helpful for interventions aimed at the prevention of mental illness. The detailed and deep understanding of the development of the mind and human development provided by psychoanalytic theory is very helpful when thinking about the complexities of when and how to most appropriately intervene. The SAPC aims to earn the respect and credibility of the Department of Health by showing how psychoanalytic thinking can help in this difficult context and that primary health care interventions based on psychoanalytic principles have a lot to offer in the area of prevention. This is a very long term goal that will require a lot of tenacity and research to achieve. 
The future of psychoanalysis in South Africa requires the ongoing and important debate around and tension between approach and method. Our capacity to keep questioning what works, and our flexibility to adapt concepts without loosing the essence, our willingness to take risks and to tread where angels fear to tread; and our capacity to bear the painful and overwhelming reality we find ourselves in is key.

\section{References}

Ivey, G. (1998). Pure Gold or Therapeutic Alloy? Some issues raised by the conference "Change: Psychoanalytic Perspectives". Psychology in Society (PINS), 23, 52-57.

Solms, M. (2010). The Establishment of an Accredited Psychoanalytic Training Institute in South Africa. Psycho-Analytic Psychotherapy in South Africa, 18 (1), 13-19.

Storck, E. (2010). The Launch of the South African Psychoanalytic Confederation: A Witness Report. Psycho-Analytic Psychotherapy in South Africa, 18(1),1-12.

Freud, S. (1919). Lines of advance in psycho-analytic therapy. Standard Edition Vo. 17 (pp. 159-168). London: The Hogarth Press.

Freud, S. (1935). Postscript to "An Autobiographical Study". Standard Edition Vol. 20, (pp. 71-74). London: The Hogarth Press.

Bion, W. R. (1962). A theory of Thinking. International Journal of Psycho-Analysis, 43, 306-310.

Kaminer, D. \& Eagle, G. (2011). Traumatic Stress in South Africa. South Africa: Wits University Press.

SAPC Pocket Directory. http://www.sapc.org.za/notices/sapc-pocket-directory. Winnicott, D.W. (1965). The Maturational Processes and the Facilitating Environment. London: Hogarth Press.

\section{Websites}

SAPI/SAPA: http://www.sapsychoanalysis.org

SAPC: http://www.sapc.org.za

Ububele: http://www.ububele.org

Neuropsychoanalysis: http://www.npsafoundation.org 


\section{Annotations}

1 The question of IPA membership is central: in order to achieve the long-term goal of offering an IPA-accredited training in any country, the beginnings are small. First of all, four IPA members are needed to form an IPA Study Group, which - under rigorous supervision by an IPA Sponsoring Committee - can start training candidates. The Study Group then embarks on the long process of developing itself to the point where it can apply for Provisional Society status (after a minimum of five years and having grown to 10 IPA members), to finally become a Component Society, when fully independent status is achieved.

In 2008 Gyuri Fodor, IPA member from Vienna, relocated to South Africa after some years of involvement in the developments here. In 2009, Susan Levy from Johannesburg was granted IPA Direct Member status by the Board of the IPA. Thus the magic number of four IPA members was reached in South Africa.

2 Ububele was the brainchild of Tony and Hillary Hamburger, who donated their skills and 2000 square meters of space on the threshold of Alexandra, a township in Johannesburg, as a centre for education and psychotherapy. Firmly committed to psychoanalysis, they have created a home for numerous community and training projects. In her contribution to this paper, Mary-Anne Smith describes a number of outreach projects and the ways in which they apply the basics of psychoanalytic thought.

3 In order to appreciate the essence of this move towards normalization, it is important to know that psychotherapy does not exist as a profession in South Africa. Neither clinical psychologists nor psychiatrists, who are allowed to practice psychotherapy, would necessarily have significant own experience of treatment in the method of their choice as a part of their training at universities. Anybody interested in psychoanalytic thinking joins a reading group and undergoes therapy with senior colleagues, entirely self-motivated and without reward either in status or remuneration. Informally, this avenue is also followed by countless social workers, occupational and educational psychologists and medical personnel interested in the psychoanalytic approach. 